\title{
Basolateral Amygdala-Driven Augmentation of Medial Prefrontal Cortex GABAergic Neurotransmission in Response to Environmental Stimuli Associated with Cocaine Administration
}

\author{
Vladimir I Chefer*,', Ruizhong Wang' and Toni S Shippenberg' \\ I'Integrative Neuroscience Section, Integrative Neuroscience Branch, National Institutes of Health/National Institute on Drug Abuse/lntramural \\ Research Program, Baltimore, MD, USA
}

\begin{abstract}
Basolateral amygdala (BLA) and medial prefrontal cortex (mPFC) interactions have been implicated in cue-elicited craving and drug seeking. However, the neurochemical mechanisms underlying drug/environment associations are ill-defined. We used in vivo microdialysis and pharmacological inactivation techniques to identify alterations in mPFC glutamate (GLU) and gamma-aminobutyric acid (GABA) transmission in response to cues previously associated with experimenter-administered cocaine (COC) and the BLA contribution to these effects. Rats received alternate day injections of COC and saline (SAL) paired with a distinct environment for 6 days. Behavioral, neurochemical and immunohistochemical studies were conducted, in drug-free animals, $24 \mathrm{~h}$ after the last conditioning session. Animals exposed to a COC-paired environment demonstrated an augmented locomotor activity (LMA) relative to those exposed to the SAL-paired environment. mPFC GABA neurotransmission in the COC-paired environment was significantly increased, whereas GLU overflow was unaltered. Dual labeling of cFos and glutamic acid decarboxylase 67 immunoreactivity in mPFC neurons revealed significantly greater colocalization of these proteins following exposure to the COC-associated environment (CAE) relative to pseudoconditioned rats or rats exposed to the SAL-associated environment indicating that the conditioned neurochemical response to the COC-paired environment is associated with activation of intrinsic mPFC GABA neurons. BLA inactivation prevented the increase in LMA and the augmentation of mPFC GABA transmission produced by cue exposure. Intra-mPFC application of the AMPA/KA receptor antagonist, NBQX, produced similar effects. These findings indicate that exposure to a CAE increases mPFC GABA transmission by enhancing excitatory drive from the BLA and activation of AMPA/KA receptors on MPFC GABA neurons.

Neuropsychopharmacology (201 I) 36, 20 I8-2029; doi: I0.1038/npp.20I I.89; published online I June 20I I
\end{abstract}

Keywords: basolateral amygdala; cocaine; drug-associated environment; glutamate; GABA; medial prefrontal cortex

\section{INTRODUCTION}

Exposure to environmental stimuli associated with the use of psychostimulants and other drugs of abuse elicits craving in human addicts and the reinstatement of drug seeking in experimental animals due to the association of environmental stimuli with unconditioned drug effects (Wikler, 1973; O'Brien et al, 1991). Although the importance of drugassociated cues in motivating behavior is well established, the neural substrates mediating this phenomenon are still unidentified.

\footnotetext{
* Correspondence: Dr VI Chefer, Integrative Neuroscience Section, Integrative Neuroscience Branch, NIDA/IRP, 333 Cassell Drive, Baltimore, MD 21224, USA, Tel: + I 443740 2869, Fax: + I 410 550 1692, E-mail: vchefer@intra.nida.nih.gov

Received 24 February 20 I ; revised II April 201 I; accepted 26 April 2011
}

The prefrontal cortex, a key component of the brain reward circuitry, is implicated in the development of stimulus-reward associations. Human imaging studies have shown increased activation in prefrontal cortical regions of cocaine (COC) abusers exposed to drug-related stimuli. The intensity of activation was correlated with craving, suggesting a key role of this region in mediating craving and drug seeking elicited by conditioned stimuli (Grant et al, 1996; Maas et al, 1998; Bonson et al, 2002). Evidence indicating an involvement of the medial prefrontal cortex (mPFC) in cueinduced drug seeking has also been obtained in rodent selfadministration studies (Weissenborn et al, 1997; Kalivas and McFarland, 2003; Kalivas et al, 2006). Furthermore, excitotoxic lesions of the prelimbic (PrL) subregion of the mPFC block the development of COC-induced conditioned place preference (CPP; Tzschentke and Schmidt, 1999) and exposure to an environment previously associated with COC administration increases cFos activation in the anterior cingulate (Cg1; Crawford et al, 1995; Zombeck 
et al, 2008) and PrL mPFC (Miller and Marshall, 2004, 2005).

Information about different aspects of contextual or cue associated learning access the MPFC through specific inputs from the hippocampus and amygdala (Holland and Bouton, 1999; Petrovich and Gallagher, 2003). Moreover, exposure to COC-associated cues leads to activation of efferents from the basolateral amygdala (BLA) to both the PrL cortex and nucleus accumbens (NAc; Miller and Marshall, 2005). However, fundamental questions remain as to whether glutamate (GLU) transmission from the BLA to the mPFC is necessary for the development of stimulus-drug associations. Furthermore, although a functional relationship between glutamatergic neurons and gamma-aminobutyric acid (GABA) interneurons in the mPFC is well documented, little information is available about the in vivo interactions of these neurotransmitters in the MPFC and the role of GABA interneurons in mediating behavioral responses to drug-associated cues.

Accordingly, the present studies used in vivo microdialysis in the rat to analyze changes in MPFC GLU and GABA neurotransmission that occur in response to presentation of environmental stimuli previously associated with the administration of COC or saline (SAL). Locomotor activity (LMA) in response to stimulus presentation was quantified in all animals. Pharmacological inactivation techniques and immunohistochemistry were used to delineate the role of BLA glutamatergic projections to mPFC GABA interneurons in mediating stimulus-evoked alterations in behavior and neurochemistry. We hypothesized that exposure to an environment previously associated with COC administration would lead to conditioned hyperactivity and a BLA-dependent increase in $\mathrm{mPFC}$ glutamate neurotransmission. Furthermore, given that GABAergic interneurons may be a major target of BLA afferents (Cunningham et al, 2008; Benes, 2010), we examined whether these effects would be coupled with augmentation in $\mathrm{mPFC}$ GABA neurotransmission.

\section{MATERIALS AND METHODS}

\section{Animals}

Male Sprague-Dawley rats (Charles River Laboratories, Wilmington, MA, USA; 300-350 g) were housed in facilities accredited by the American Association for the Accreditation of Laboratory Animal Care, and experiments conformed to the guidelines of, and were approved by, the NIH/ NIDA Intramural Research Program Institutional Care and Use Committee. Rats were maintained at a constant temperature $\left(22 \pm 2^{\circ} \mathrm{C}\right)$ on a 12-h light/dark cycle (light from 0700 to 1900 hours). All animal procedures in this study were performed during the light cycle (from 0900 to 1600 hours).

\section{Surgical Procedures and Drugs}

Rats were anesthetized with Equithesin (sodium pentobarbital, chloral hydrate, and magnesium sulfate; $9.72 \mathrm{mg} / \mathrm{ml}$; $3 \mathrm{ml} / \mathrm{kg}$, i.p.) and stereotaxically implanted with a unilateral microdialysis guide cannulae (CMA/11; CMA/Microdialysis, Acton, MA, USA) in the mPFC (from bregma, in $\mathrm{mm}$ : anteroposterior +3.2 , mediolateral \pm 0.6 , ventral -2.3 , Paxinos and Watson, 1998). After surgery, animals were housed singly in the colony room. They were handled and allowed a 4-5 day recovery before commencement of the experiments.

For microinjection experiments rats were implanted with bilateral 26 gauge stainless steel guide cannulae into the BLA (from bregma, in $\mathrm{mm}$ : anteroposterior -2.8 ; mediolateral \pm 4.9 ; and ventral -7.6 , Paxinos and Watson, 1998). The guide cannulae were held in place with stainless steel screws and dental acrylic and contained dummy cannulae cut flush with the end of guide cannulae.

COC hydrochloride was provided by the National Institute on Drug Abuse (Bethesda, MD, USA) and prepared in sterile SAL for systemic injection. For inactivation studies, the $\mathrm{GABA}_{\mathrm{B}}$ agonist baclofen (1 mM; Sigma-Aldrich, St Louis, MO, USA) and the $\mathrm{GABA}_{\mathrm{A}}$ agonist muscimol (0.1 mM; Sigma-Aldrich, St Louis, MO, USA) were prepared in phosphate-buffered artificial cerebrospinal fluid (aCSF) and infused into the BLA. The AMPA/KA receptor antagonist NBQX $(100 \mu \mathrm{M}$; Sigma-Aldrich, St Louis, MO, USA) was prepared in phosphate-buffered aCSF and perfused through the probe during microdialysis experiments.

\section{Conditioning and Microdialysis Procedures}

Before each conditioning session, animals were placed into clear Plexiglas chambers $\left(26 \times 26 \times 33 \mathrm{~cm}^{3}\right)$ and connected to a tethering system identical to that used during microdialysis. After a variable $(1-3 \mathrm{~h}$ ) baseline period (to avoid confounds associated with expectancy), black or white removable walls were placed along the external walls of the chambers to create two distinct environments (Figure 1). Rats were then injected with SAL $(1.0 \mathrm{ml} / \mathrm{kg}$, i.p.) or $\operatorname{COC}(20 \mathrm{mg} / \mathrm{kg}, 1.0 \mathrm{ml} / \mathrm{kg}$, i.p. $)$ in the chambers where they then remained for another $1 \mathrm{~h}$. Place conditioning sessions (three COC; three SAL) were conducted once each day for 6 days. At the end of each session, the tether was removed and the rat returned to its home cage. Both injection order (drug $v s$ vehicle) and environmental-drug pairing were counterbalanced within each experimental group. Microdialysis was conducted in the drug-free state, $24 \mathrm{~h}$ following the last conditioning session. Half of the animals were exposed to the SAL-associated environment and the other half to the COC-associated environment (CAE). A pseudo-conditioned group, in which rats received COC injections in their home cages (unpaired to the test environment), served as control. They were usually injected with $\mathrm{COC}$ in the morning and exposed to the testing apparatus in the afternoon. LMA was measured throughout dialysis sessions using a Tru-Scan activity monitoring system (Coulbourn Instruments, Whitehall, PA, USA).

For microinjection experiments, animals received mock infusions during each conditioning session. At $20 \mathrm{~min}$ after placement in the clear-walled chamber, rats were gently restrained, and the dummy cannulae removed. The injector cannulae, which was connected to a microinjection pump, was partially inserted into the guide cannulae for $2 \mathrm{~min}$ after which it was removed and the animal placed back into the conditioning chamber. 


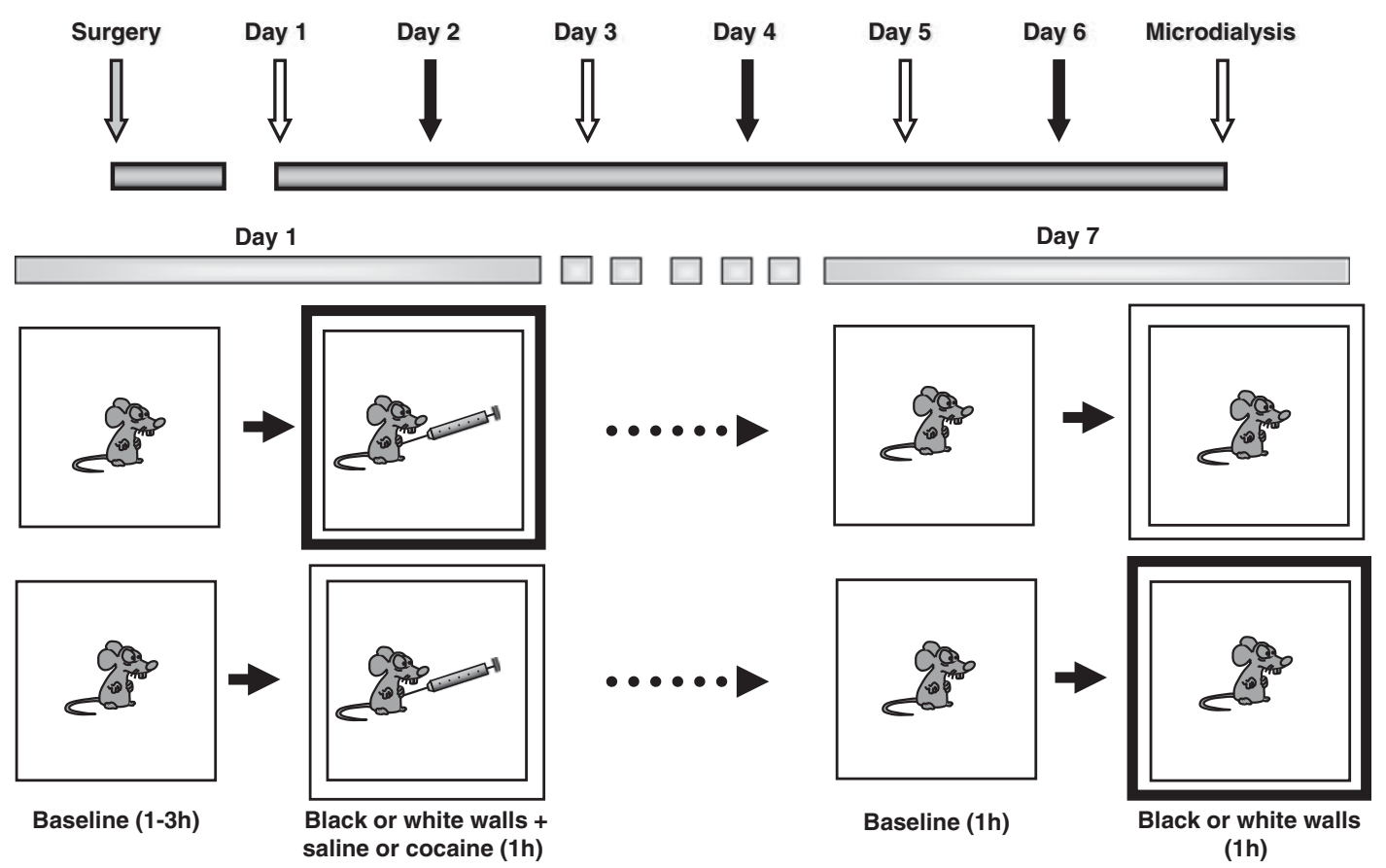

Figure I Schematic representation of experimental procedure. Following recovery from surgery, administration of cocaine and saline were paired with distinct environmental cues. Six conditioning sessions (three cocaine; three saline) were conducted. Before each session, animals were placed into a clear Plexiglas test chamber $\left(26 \times 26 \times 33 \mathrm{~cm}^{3}\right)$ for $1-3 \mathrm{~h}$. Conditioning sessions commenced with the introduction of black or white walls to the chambers and injection of animals with either saline $(1.0 \mathrm{ml} / \mathrm{kg}$, i.p.) or cocaine $(1.0 \mathrm{ml} / \mathrm{kg}, 20 \mathrm{mg} / \mathrm{kg}$, i.p.). Treatment order, drug-environment pairing and order of environment presentation were counterbalanced between groups. Rats were tested $24 \mathrm{~h}$ later, in the drug-free state, for changes in locomotor activity (LMA) and mPFC neurotransmission that occur on exposure to the cocaine- or saline-associated cues. For additional details, see Materials and Methods ('Conditioning and Microdialysis Procedures').

Microdialysis experiments were conducted as previously described (Chefer et al, 2005, 2009; Supplementary Materials and Methods). On the day of the experiment, fresh aCSF was perfused at $1 \mu \mathrm{l} / \mathrm{min}$ and following a $1 \mathrm{~h}$ equilibration period, basal dialysate samples were collected at $5 \mathrm{~min}$ intervals for $1 \mathrm{~h}$. The black or white walls previously paired with injection of SAL or COC were then placed outside of the clear Plexiglas walls and dialysate samples were again collected for $1 \mathrm{~h}$. In experiments assessing the effects of AMPA/KA receptor inactivation, half of the animals were perfused with aCSF (SAL/VEH; COC/VEH) and the other half with the AMPA/KA receptor antagonist NBQX $(100 \mu \mathrm{M})$ in aCSF (SAL/NBQX; COC/NBQX) for the duration of microdialysis experiments.

\section{Microinjections during Microdialysis Experiments}

The BLA was inactivated $40 \mathrm{~min}$ before introduction of the COC- or SAL-associated cues by microinfusion of a solution containing the $\mathrm{GABA}_{\mathrm{B}}$ agonist baclofen $(1 \mathrm{mM})$ and the $\mathrm{GABA}_{\mathrm{A}}$ agonist muscimol $(0.1 \mathrm{mM}$; Peters et al, 2008). GABA agonists (baclofen/muscimol-BM) or vehicle were administered bilaterally using a 33 gauge injection cannulae that extended $1.0 \mathrm{~mm}$ from the guide cannulae, and a microsyringe pump (CMA/100; CMA/Microdialysis, Acton, MA, USA). The infusion volume of $0.5 \mu 1 /$ site was delivered at a flow rate of $0.5 \mu \mathrm{l} / \mathrm{min}$. The injection cannulae were left in place for 1-2 min to allow for diffusion. For microinfusions, animals were gently removed from the experimental chambers and then returned following the $\sim 5 \mathrm{~min}$ microinfusion procedure. Baseline dialysate samples were then collected for an additional $40 \mathrm{~min}$ before cue exposure.

\section{Histological Analysis}

See Supplementary Materials and Methods.

\section{Chromatographic Analysis of Brain Microdialysates}

Amino-acid content was quantified using a capillary electrophoresis P/ACE MDQ system (Beckman, Fullerton, CA, USA) coupled to an external ZETALIF laser-induced fluorescence detector (Picometrics, France). The excitation was performed by a diode laser (Picometrics) at a wavelength of $410 \mathrm{~nm}$. The emission wavelength was $490 \mathrm{~nm}$. Separations were carried out in a fused-silica capillary $(50 \mu \mathrm{m}$ internal diameter, $350 \mu \mathrm{m}$ outside diameter; Polymicro Technologies, Phoenix, AZ, USA). The capillary was $62 \mathrm{~cm}$ long $(46 \mathrm{~cm}$ from injection to detection window). An automatic derivatization procedure suitable for unattended derivatization and injection of the samples by the P/ACE MDQ system was used (Chefer et al, 2009; Supplementary Materials and Methods).

\section{Immunohistochemistry Experiments}

Immunohistochemistry was conducted in parallel groups of rats conditioned as described. At $90 \mathrm{~min}$ after exposure to 
either the COC- or SAL-paired environment, rats were anesthetized with Equithesin and perfused transcardially with $0.1 \mathrm{M}$ PBS, pH 7.4, followed by $10 \%$ buffered formalin. The brains were removed and post-fixed overnight at $4{ }^{\circ} \mathrm{C}$, then prefrontal cortex regions were dissected and transferred to $30 \%$ sucrose for $48 \mathrm{~h}$ at $4{ }^{\circ} \mathrm{C}$. Every 10 th coronal section $(25 \mu \mathrm{m})$ was collected at levels 3.7-2.7 mm (PrL-PFC area) from bregma (Paxinos and Watson, 1998) using a cryostat. Collected sections were rinsed in $0.1 \mathrm{M}$ PBS, followed by preincubation in $0.1 \mathrm{M}$ PBS containing $5 \%$ normal goat serum (NGS), then incubated for $48 \mathrm{~h}$ at $4{ }^{\circ} \mathrm{C}$ in $0.1 \mathrm{M}$ PBS containing rabbit anti-Fos polyclonal antibody (PC-38; 1:20 000; Oncogene Science, Cambridge, MA) and $2 \%$ NGS. The sections were then rinsed in $0.1 \mathrm{M}$ PBS and incubated in $0.1 \mathrm{M}$ PBS containing mouse anti-glutamic acid decarboxylase $67\left(\mathrm{GAD}_{67}\right)$ monoclonal antibody (1:10 000, Millipore, MA) and 2\% NGS for $48 \mathrm{~h}$. The sections were then rinsed again in $0.1 \mathrm{M}$ PBS and incubated with a secondary antibody mixture of goat anti-rabbit IgG conjugated with Alexa fluor 488 and goat anti-mouse IgG-labeled by Alexa fluor 594 in $0.1 \mathrm{M}$ PBS and $2 \%$ NGS for $2 \mathrm{~h}$ at room temperature. After rinsing with PBS, sections were mounted onto slides and dried before coverslipping. Immunoreactivity was quantified using a spinning disk confocal microscope equipped with a $\times 20$ objective (PerkinElmer, Waltham, MA, USA). $Z$-stack images $(0.5 \mu \mathrm{m})$ extending from layers II-V of the center region of PrL cortex were captured with a CCD digital imaging camera. All cells immunoreactive for $c$ Fos and $\mathrm{GAD}_{67}$ on the images were counted separately, and then merged for double labeling of cFos and $\mathrm{GAD}_{67}$ (Miller and Marshall, 2004). The counts were then averaged to give a mean number of each immunoreactive cell type per section. These counts were then divided by the area of the corresponding region to give cells counts per square millimeter. The counting was conducted blindly, then decoded and regrouped.

\section{Data Analysis}

Dialysate GABA and GLU concentrations are expressed as absolute values $(\mathrm{nm})$ or as a percentage change from baseline levels. Repeated-measures ANOVA with one between factor (salience: SAL- vs CAE) and two within factors (change in environment: baseline $v s$ black/white walls and time) was used to analyze time-course data in initial microdialysis experiments. Repeated-measures ANOVA with two between factors (salience: SAL- vs CAE and pretreatment: vehicle $v s$ drug) and two within factors (change in environment: baseline $v s$ black/white walls and time) was used to analyze data regarding inactivation of the BLA or $\mathrm{MPFC}$ AMPA/KA receptors. In addition, LMA and neurotransmitter levels following introduction of the new environment were converted to area under the curve (AUC) values using the standard trapezoid method (Gibaldi and Perier, 1975). The data were analyzed using one- or two-way ANOVA (depending on the experiment) followed by Bonferroni's multiple comparison test. Immunohistochemistry data are expressed as number of immunoreactive cells per square millimeter and were analyzed using one- or two-way ANOVA (depending on experiment) followed by Bonferroni's multiple comparison test. Data are presented as mean \pm standard error of the mean. The accepted value of significance was $p \leqslant 0.05$.

\section{RESULTS}

\section{Alterations in Locomotor Activity in Response to Environmental Cue Exposure}

Exposure of animals to either the SAL or COC-paired environment increased LMA relative to basal levels (repeated-measures ANOVA: $\mathrm{F}_{(1,22)}=17.4$; $p<0.01$ ). However, locomotor activation was significantly greater in rats exposed to the CAE (environment $\times$ salience $\times$ time interaction: $\mathrm{F}_{(4,99)}=2.47 ; p=0.04$; drug $v s$ SAL environment: $\mathrm{F}_{(1,22)}=5.98 ; p=0.02$; AUC values: $p=0.04, t=2.1, \mathrm{df}=20$; Figure $2 \mathrm{a}$ and $\mathrm{b}$ ) indicating that animals could differentiate the two cues.

\section{Basal and Cue-Evoked Changes in mPFC GABA and GLU Overflow}

Figure 2 shows basal and cue-evoked GABA and GLU overflow in the mPFC. Basal overflow did not differ between experimental groups (GABA: $\mathrm{F}_{(1,10)}=0.002 ; p=0.97$; Figure $2 \mathrm{c}$ and d; GLU: $\mathrm{F}_{(1,10)}=0.18 ; p=0.68$; Figure $2 \mathrm{e}$ and $\mathrm{f}$ ). Repeated-measures ANOVA of GABA overflow (between factor-environmental salience: SAL- $v s$ CAE; within factors - change of environment: baseline $v s$ black/white walls and time) revealed a significant main effect of change of environment $\left(\mathrm{F}_{(1,10)}=16.8 ; p<0.01\right)$ and a significant interaction between change of environment and environmental salience $\left(\mathrm{F}_{(1,10)}=11.1 ; p<0.01\right)$. No effect on GLU overflow was seen $\left(\mathrm{F}_{(1,10)}=1.96 ; p=0.19\right.$ and $\mathrm{F}_{(1,10)}=0.11$; $p=0.92)$. Exposure to the SAL-associated cues did not alter GABA $\left(\mathrm{F}_{(1,6)}=0.23 ; p=0.64\right.$; Figure $2 \mathrm{c}$ and $\left.\mathrm{d}\right)$ or GLU overflow $\left(\mathrm{F}_{(1,6)}=0.95 ; p=0.36\right.$; Figure $2 \mathrm{e}$ and $\left.\mathrm{f}\right)$. Consequently, no change in the GLU/GABA ratio $\left(\mathrm{F}_{(1,6)}=0.01\right.$; $p=0.98$; data not shown) was seen. In contrast, environmental cues associated with $\mathrm{COC}$ induced a significant increase in mPFC GABA overflow $\left(\mathrm{F}_{(1,5)}=103.9 ; p=0.01\right.$; Figure $3 \mathrm{c}$ and $\mathrm{d}$ ). GLU overflow, however, was not significantly altered $\left(\mathrm{F}_{(1,5)}=1.98 ; p=0.23\right.$; Figure $2 \mathrm{e}$ and f). As a consequence of the increase in GABA overflow and no change in GLU, the GLU/GABA ratio was decreased $\left(\mathrm{F}_{(1,5)}=18.02 ; p=0.01\right.$; data not shown), indicating increased inhibitory drive.

\section{Influence of Cue Exposure on mPFC cFos Expression}

Increased GABA overflow may result from activation of GABA neurons located in the MPFC or from activation of GABA neurons projecting to this region. To investigate the source of the GABA increase (intrinsic vs extrinsic), we characterized cFos and $\mathrm{GAD}_{67}$ immunoreactivity in the $\mathrm{mPFC}$ following exposure of rats to either the SAL- or CAE. $\mathrm{GAD}_{67}$ immunoreactivity did not differ between experimental groups (one-way ANOVA $\mathrm{F}_{(2,29)}=1.26 ; p=0.3$; Figure 3a). cFos immunoreactivity was significantly greater in $\mathrm{mPFC}$ neurons following exposure to the CAE as compared with the pseudo-conditioning and SALassociated environment groups (one-way ANOVA $\mathrm{F}_{(2,29)}=14.43 ; p<0.01 ;$ Bonferroni's test: $t=5.1 ; p<0.01$ 

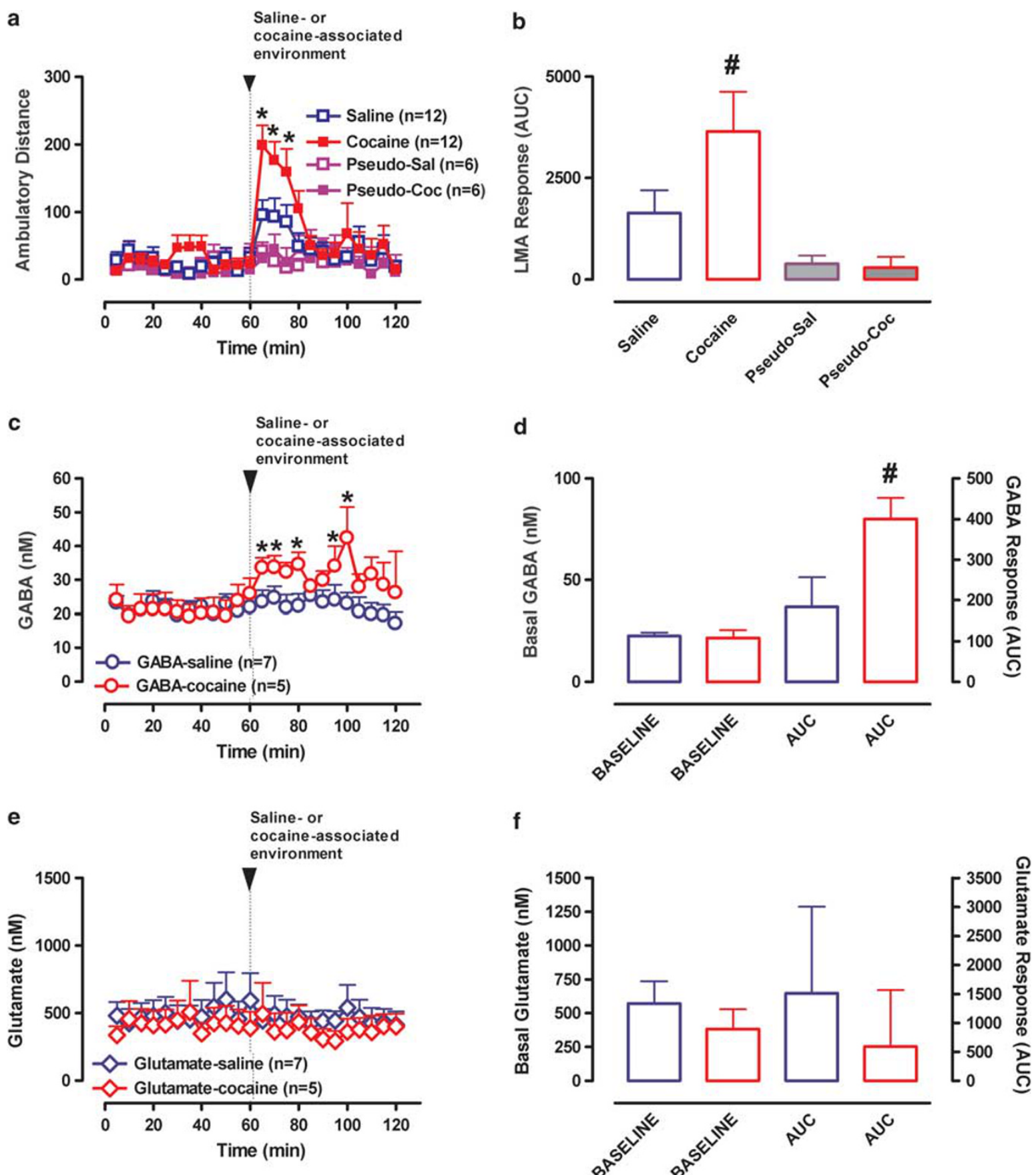

Figure 2 LMA and mPFC GABA/GLU levels during baseline and on exposure to the cocaine- or saline-associated environment. (a) Time course of $L M A$ before and after introduction of the black or white walls, which were previously associated with saline $(n=12$, open blue symbols) or cocaine ( $n=12$, closed red symbols) administration, or unpaired to injections (Pseudo-Sal: $n=6$, open purple symbols; Pseudo-Coc: $n=6$, closed purple symbols). Data are expressed as the means \pm SEM; $n=$ number of animals/experimental group. (b) Bar graphs of area under the curve (AUC) values for LMA (means \pm SEM). (c) Time course of mPFC GABA overflow before and after introduction of the saline- $(n=7$, open blue circles) or cocaine- ( $n=5$, open red circles) associated environment. Data are expressed as the means \pm SEM; $n=$ number of animals/experimental group. (d) Bar graphs of average basal levels and AUC values for the mPFC GABA overflow (means \pm SEM). (e) Time course of mPFC GLU overflow before and after introduction of the saline- $(n=7$, open blue symbols) or cocaine- ( $n=5$, open red symbols) associated environment. Other details are as in (c). ( $f$ ) Bar graphs of average basal levels and AUC values for mPFC GLU overflow (means \pm SEM). *Indicates significant changes from baseline $(p \leqslant 0.05)$. "Indicates significant difference between the salineand cocaine-associated environments $(p \leqslant 0.05)$.

and $t=4.0 ; p<0.01$, respectively Figure $3 \mathrm{~b})$. The degree of cFos and $\mathrm{GAD}_{67}$ overlap was significantly higher after exposure to the CAE than after the SAL-associated environment $\quad\left(\mathrm{F}_{(2,27)}=20.5 ; \quad p<0.01 ; \quad t=5.7 ; \quad p<0.01\right.$;
Figure 3c) or in pseudo-conditioned controls $\left(\mathrm{F}_{(2,27)}=20.5 ; p<0.01 ; t=5.1 ; p<0.01\right.$; Figure $\left.3 \mathrm{c}\right)$. These results indicate that the increase in GABA levels that occurs during presentation of $\mathrm{COC}$-associated cues is due, at least 

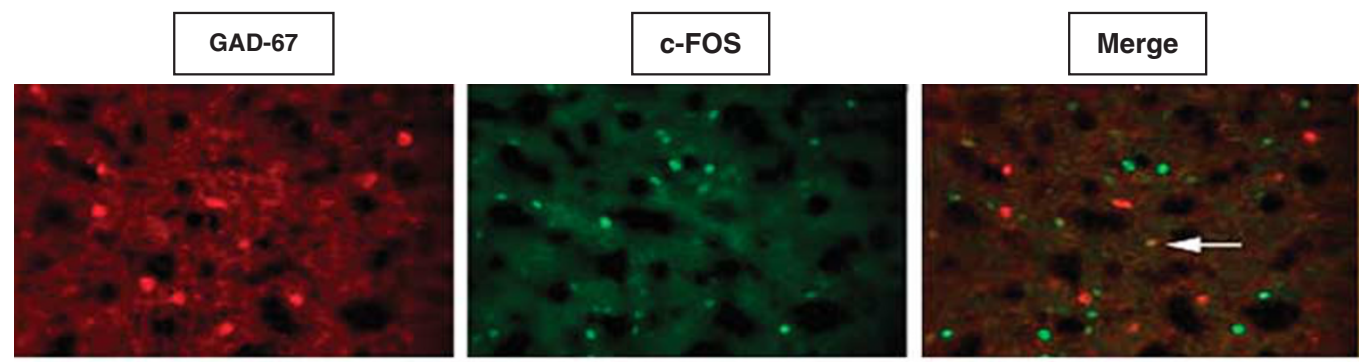

\section{Pseudo- \\ conditioning}
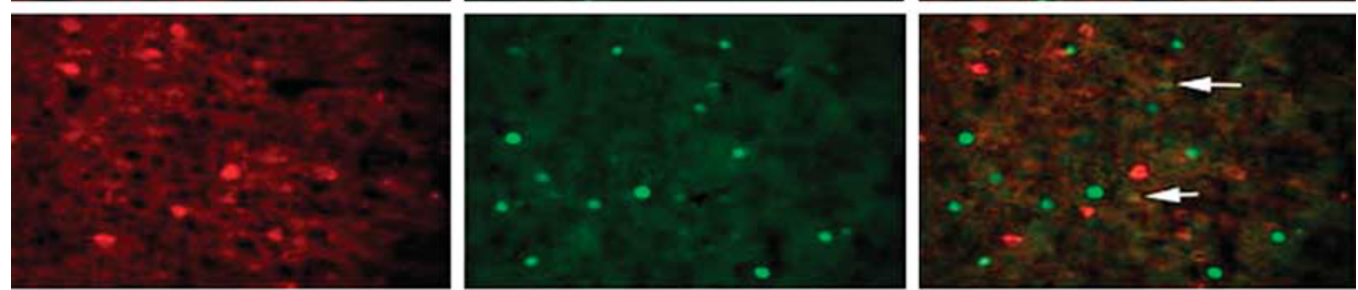

\section{Saline- \\ associated \\ environment}
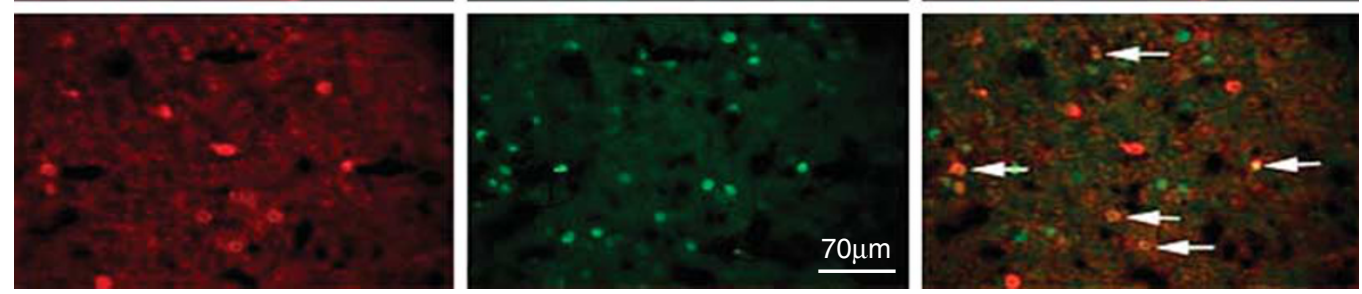

\section{Cocaine- \\ associated \\ environment}
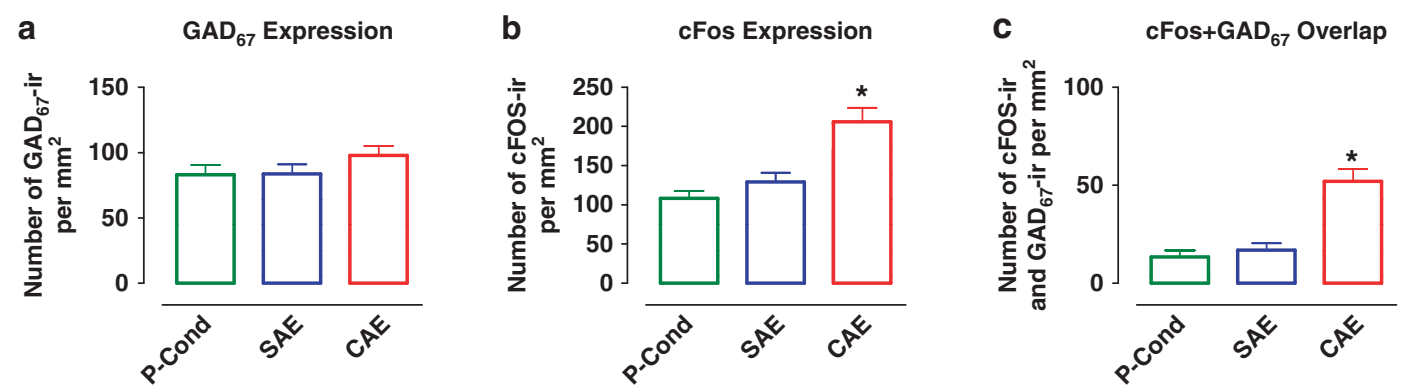

Figure $3 \mathrm{GAD}_{67}$ and $c$ Fos colocalization after exposure to the cocaine- or saline-associated environment. Photomicrographs of individually immunolabeled GAD $67-I R$, cFos-IR neurons and double-labeled (GAD $67-I R$ and cFos-IR) neurons (white arrows) in representative animals. Scale bar, $70 \mu$ m. (a) Quantification of $\mathrm{GAD}_{67}$ expression $/ \mathrm{mm}^{2}$ in pseudo-conditioned animals (control, $n=10$ ) and those exposed to the saline- or cocaine-associated environment (SAE, $n=10$ and CAE, $n=10$, respectively). (b) Quantification of cFos expression $/ \mathrm{mm}^{2}$ in the same groups of animals as in (a). (c) Quantification of cFos-GAD 67 overlap/mm $\mathrm{mm}^{2}$ in the same groups of animals as in (a). Data are expressed as the means \pm SEM; $n=$ number of animals/ experimental group. A greater number of cFos-IR neurons as well as cFos-GAD 67 double-labeled neurons were found in animals exposed to cocaineassociated environment. *Indicates significant difference between groups via one-way ANOVA $(p \leqslant 0.05)$.

partially, to activation of GABAergic neurons intrinsic to the mPFC.

\section{Effects of BLA Inactivation on Cue-Evoked Alterations in Locomotor Activity, mPFC GABA Overflow and cFos Expression}

To elucidate whether projections from the BLA to the MPFC cortex are critical for the observed increase in GABA overflow, we performed microdialysis experiments in which the BLA was inactivated before presentation of the COC- or SAL-associated cues (Figure 4). Two-way repeated-measures ANOVA (between factors: environmental salience and BLA inactivation; within factors: change of environment and time) showed a significant main effect of salience $\left(\mathrm{F}_{(1,15)}=8.25 ; p=0.01\right)$ and a significant interaction between change of environment and environmental salience for GABA overflow $\left(\mathrm{F}_{(1,15)}=8.51 ; p=0.011\right)$. There was no significant effect of BLA microinfusion $\left(\mathrm{F}_{(1,15)}=1.35\right.$; $p=0.26)$ and no microinjection $\times$ time interaction $\left(\mathrm{F}_{(1,15)}=0.74 ; p=0.66\right)$. Analysis of the environment $\times$ salience interaction revealed a significant effect of change of environment $\left(\mathrm{F}_{(1,8)}=7.67 ; p=0.024\right)$ and BLA inactivation $\left(\mathrm{F}_{(1,8)}=5.58 ; p<0.051\right)$ only in rats exposed to the CAE. Thus, exposure to the CAE produced a significant increase in GABA overflow, which was blocked by microinfusion of BM into the BLA (Figure $4 a, c$ and e). Two-way repeated-measures ANOVA of LMA data showed a significant main effect of change of environment $\left(\mathrm{F}_{(1,17)}=10.52 ; p=0.005\right)$, but no significant environment $\times$ salience interaction $\left(\mathrm{F}_{(1,17)}=0.42 ; p=0.53\right)$. However, analysis of AUC data revealed a significant effect of BLA inactivation in rats exposed to the CAE (one-way ANOVA $\mathrm{F}_{(3,20)}=8.97 ; \quad p<0.01 ; \quad$ Bonferroni's multiple 

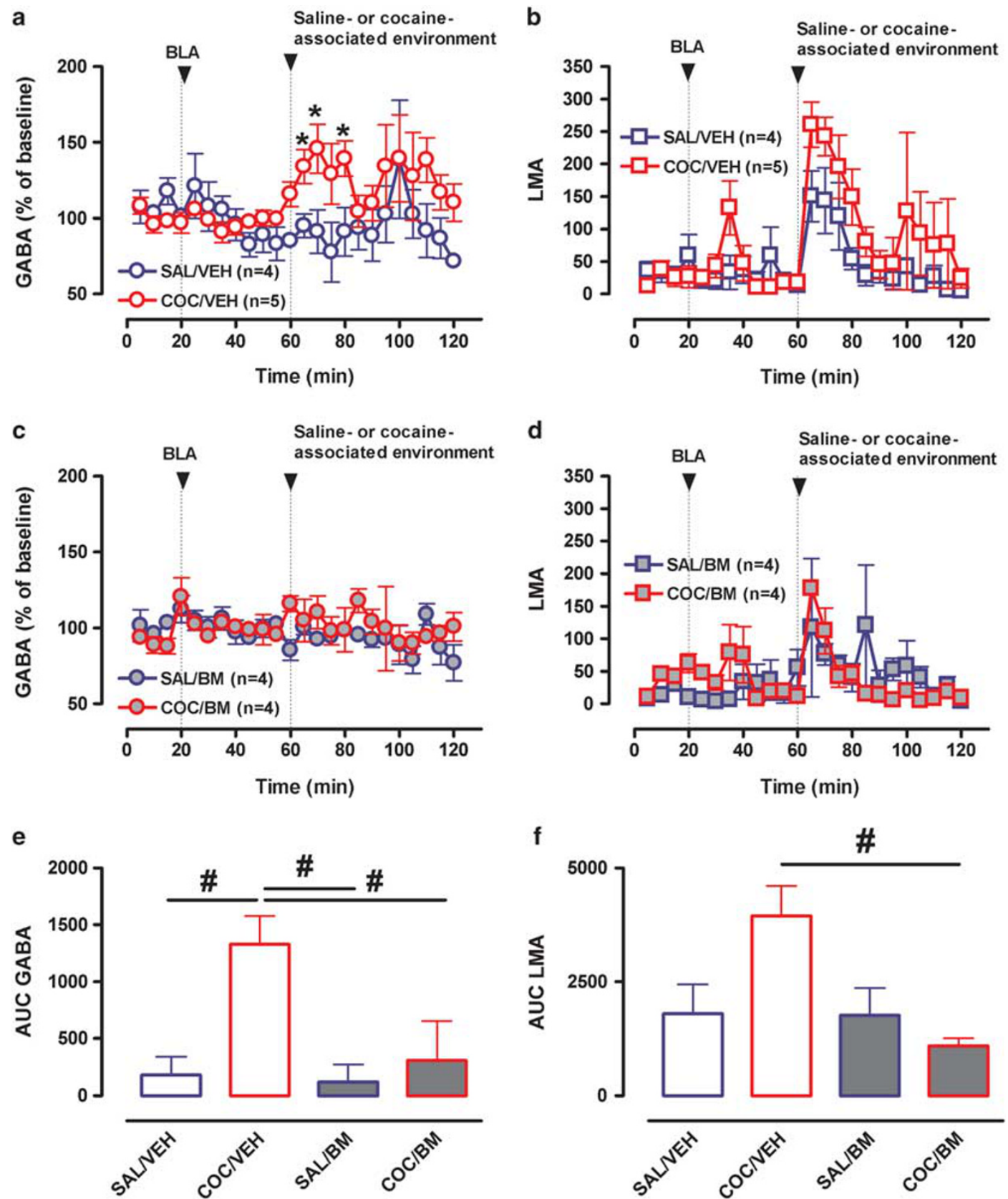

Figure 4 Influence of BLA inactivation on LMA and mPFC GABA neurotransmission produced by exposure to the cocaine- or saline-associated environment. (a) Time course of mPFC GABA overflow before and after introduction of the saline- (blue circles) or cocaine- (red circles) associated environment in rats that received microinjections of either vehicle (VEH, open symbols) or the $G_{A B A}$ (baclofen, I mM)/GABA $\left(m_{A}\right.$ uscimol, 0.1 mM) agonists (BM, closed symbols) into the BLA. (b) Time course of LMA before and after introduction of the saline- (blue squares) or cocaine- (red squares) associated environment following BLA microinjection of either vehicle (VEH, open symbols) or BM (closed symbols). (c) Bar graphs of AUC values for mPFC GABA overflow expressed as means \pm SEM. (d) Bar graphs of AUC values for LMA expressed as means \pm SEM. *Indicates significant changes from baseline $(p \leqslant 0.05)$. "Indicates significant difference between groups (one-way ANOVA; $p \leqslant 0.05$ ).

comparison test: $t=4.46 ; p<0.01)$ indicating that inactivation of BLA decreased the conditioned LMA response to COC-paired cues (Figure $4 \mathrm{~b}, \mathrm{~d}$ and $\mathrm{f}$ ).

Figure 5 demonstrates $c$ Fos and $\mathrm{GAD}_{67}$ immunoreactivity in the mPFC in pseudo-conditioned controls and animals exposed to the CAE. In the latter group, half of the animals had vehicle infusions into the BLA and the other half had bilateral inactivation of the BLA. Analogous to the data shown in Figure 3, $\mathrm{GAD}_{67}$ immunoreactivity did not differ between experimental groups (one-way ANOVA $\mathrm{F}_{(2,31)}=0.6 ; p=0.5$; Figure 5a). cFos immunoreactivity was significantly greater following exposure to the CAE in vehicle-infused rats (Figure 5b; CAE/VEH) as compared with the pseudo-conditioned (Figure $5 \mathrm{~b}$; CONTROL) group (one-way ANOVA $\mathrm{F}_{(2,31)}=15.4 ; p<0.01 ;$ Bonferroni's multiple comparison test: $t=4.97 ; p<0.01)$. However, following BLA inactivation, cFos immunoreactivity produced by exposure to the CAE did not differ from that of the 

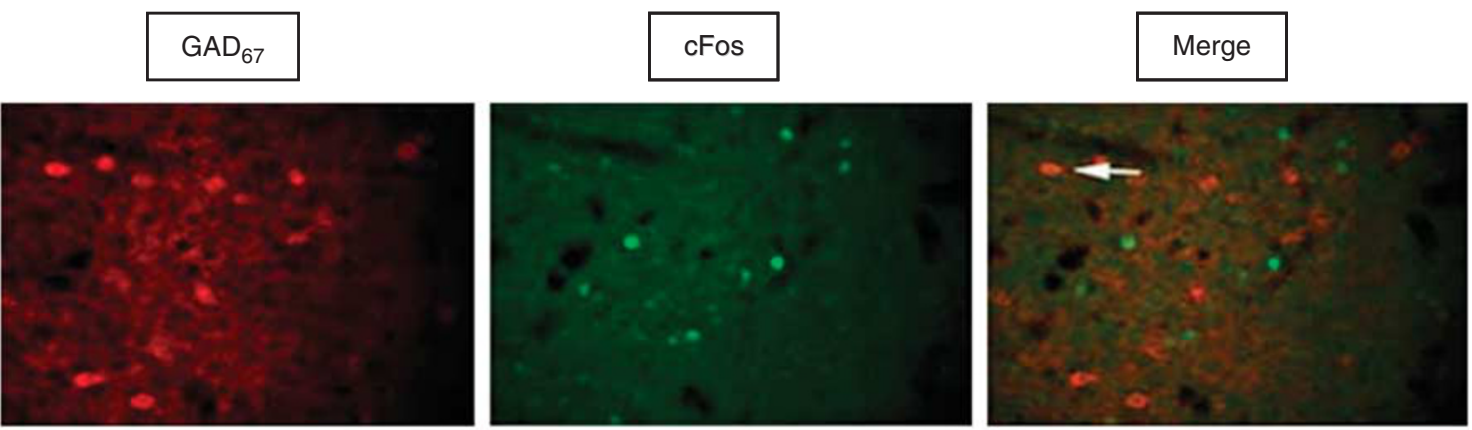

Pseudo-

conditioning
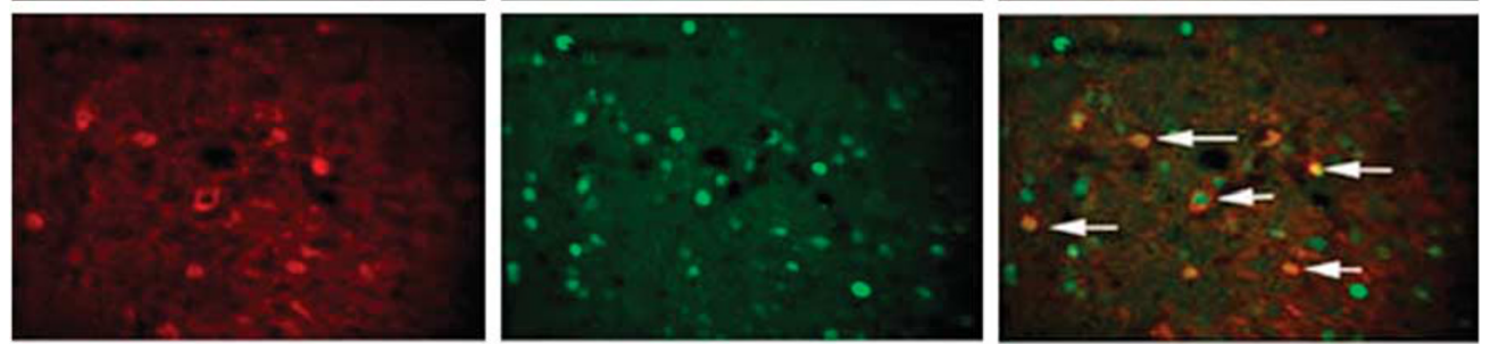

Cocaine-

associated

environment
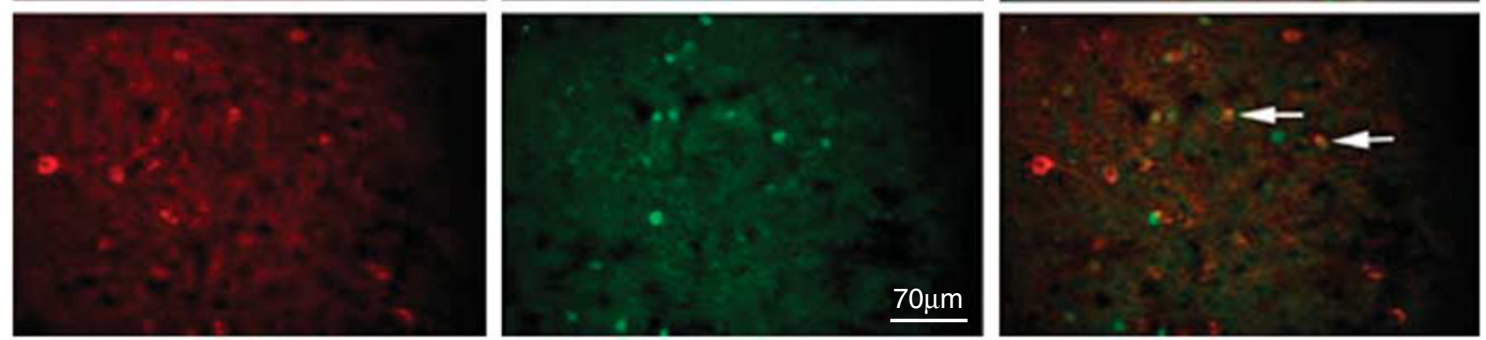

Cocaine-

associated

Environment /

Inactivation of the BLA

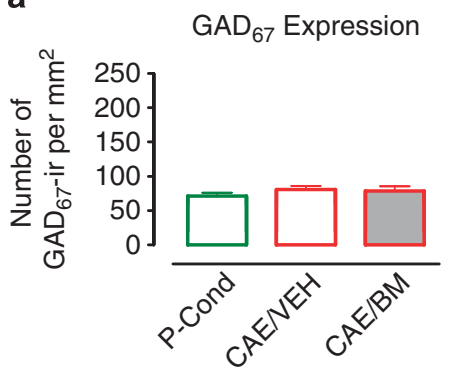

b

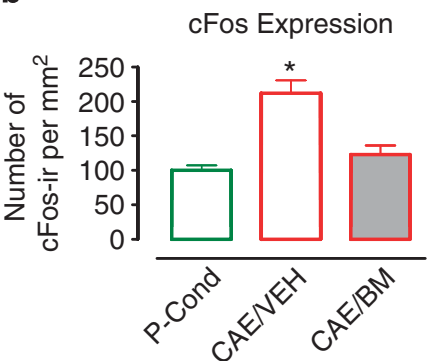

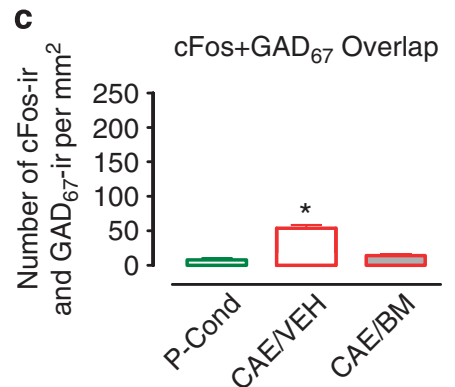

Figure 5 Influence of $B L A$ inactivation on the increase in $G_{A D}$ and $c F o s$ colocalization produced by exposure to the cocaine-associated environment. Photomicrographs of individually immunolabeled $G A D_{67}-I R$ and cFos-IR neurons and double-labeled (GAD $67-I R$ and cFos-IR) neurons (white arrows) in representative animals that were pseudo-conditioned or tested following exposure to the cocaine-associated environment with or without inactivation of the BLA. Scale bar, $70 \mu \mathrm{m}$. (a) Quantification of $\mathrm{GAD}_{67}$ expression $/ \mathrm{mm}^{2}$ in pseudo-conditioned animals (control) and those exposed to the cocaineassociated environment after intra-BLA microinjections of vehicle or baclofen/muscimol (CAE/NEH and CAE/BM, respectively). (b) Quantification of cFos expression $/ \mathrm{mm}^{2}$ in the same groups of animals as in (a). (c) Quantification of cFos-GAD 67 overlap $/ \mathrm{mm}^{2}$ in the same groups of animals as in (a). A significantly greater number of cFos-IR neurons as well as $c F 05-G A D_{67}$ double-labeled neurons were found in animals exposed to the cocaine-associated environment. *Indicates significant difference between groups (one-way ANOVA; $p \leqslant 0.05$ ).

pseudo-conditioned group (Figure 5b; CONTROL vs CAE/ $\mathrm{BM}$ group; $t=1.01 ; p>0.05)$. Accordingly, whereas vehicletreated rats exhibited a significant increase in cFos positive, $\mathrm{GAD}_{67}$ immunoreactive neurons following exposure to the CAE relative to pseudo-conditioned controls $\left(\mathrm{F}_{(2,28)}=27.01 ; p<0.01 ; t=7.09 ; p<0.01\right.$; Figure $5 \mathrm{c} ; \mathrm{CAE} /$ VEH vs CONTROL), this effect was blocked by inactivation of the BLA $(t=0.98 ; p>0.05$; Figure $5 c ;$ CAE/BM $v s$ CONTROL). These results indicate that activation of GABA neurons in the $\mathrm{MPFC}$, which occurs during presentation of COC-associated cues, is mediated by excitatory inputs from the BLA.
Influence of AMPA/KA Receptor Inactivation on MPFC GABA Overflow Evoked by Exposure to the Cocaine or Saline-Associated Environment

To examine the role of AMPA/KA receptors in the cueinduced increase in mPFC GABA levels the AMPA/KA receptor antagonist, NBQX $(100 \mu \mathrm{M})$, or aCSF was perfused into the $\mathrm{MPFC}$ via reverse-dialysis throughout microdialysis and GABA overflow quantified (Figure 6). Two-way repeated-measures ANOVA (between factors: environmental salience and NBQX treatment; within factors: change of environment and time) revealed a significant interaction 
between change of environment and environmental salience $\left(\mathrm{F}_{(1,17)}=4.34 ; p=0.05\right)$. Further analysis revealed an interaction between change of environment and NBQX treatment $\left(\mathrm{F}_{(1,8)}=5.37 ; p<0.05\right)$. A significant effect of AMPA/KA receptor blockade was only apparent in rats exposed to the CAE $\left(\mathrm{F}_{(1,8)}=5.33 ; p=0.05\right)$, indicating that activation of $\mathrm{MPFC}$ AMPA/KA receptors is necessary for the increase in GABA overflow produced by exposure to the CAE (Figure 6a, b and $c$ ).
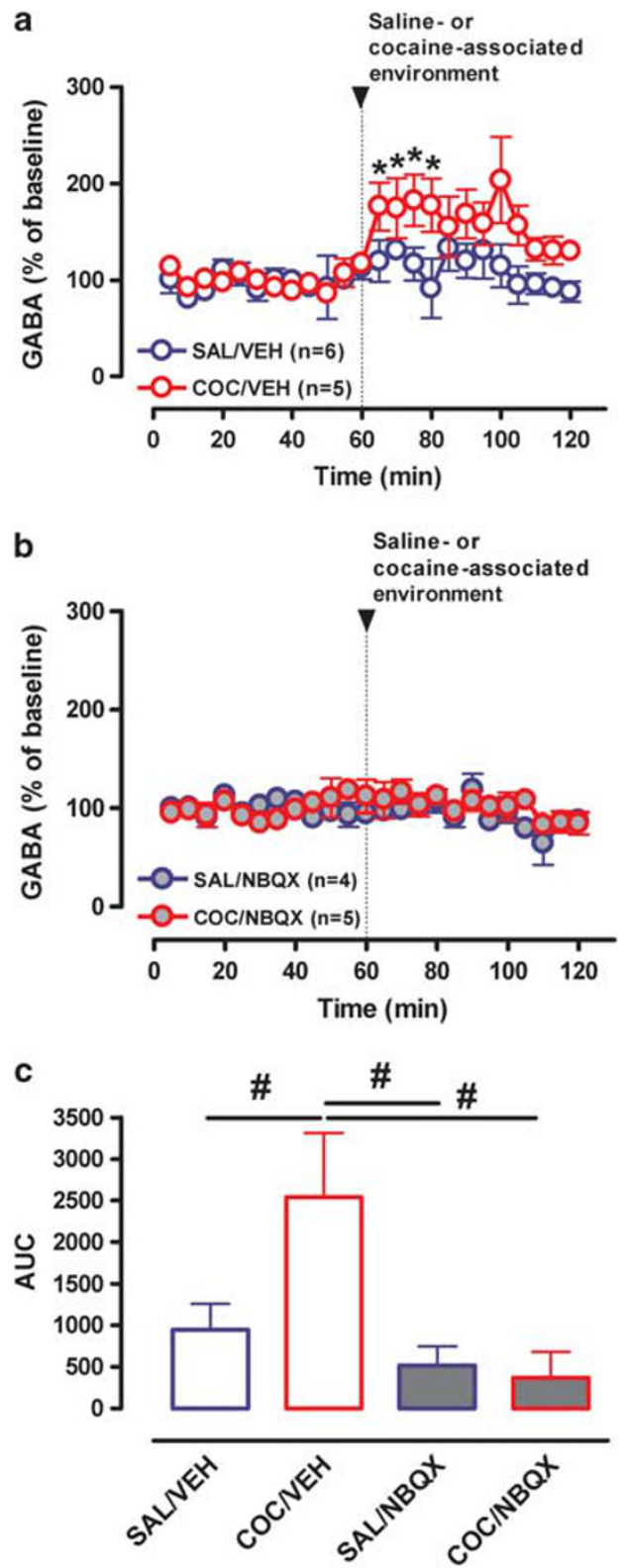

Figure 6 Influence of inactivation of AMPA/KA receptors in the MPFC on cue-induced GABA overflow. (a) Time course of mPFC GABA overflow before and after introduction of the saline- (blue circles) or cocaine- (red circles) associated environment during reverse microdialysis of vehicle (aCSF, VEH, open symbols) or the AMPA/KA receptor antagonist NBQX (NBQX in aCSF, NBQX, closed symbols). (b) Bar graphs of AUC values for mPFC GABA overflow expressed as means \pm SEM. *Indicates significant changes from average baseline $(p \leqslant 0.05)$. \#Indicates significant difference between groups via one-way ANOVA $(p \leqslant 0.05)$.

\section{DISCUSSION}

The present studies demonstrate that animals exposed to an environment associated with repeated COC administration exhibit conditioned hyperactivity and a significant increase in mPFC GABA neurotransmission. cFos immunoreactivity in $\mathrm{mPFC} \mathrm{GAD}_{67}$-labeled neurons was significantly greater following exposure to the COC-paired environment indicating that the increase in GABA levels is associated with activation of intrinsic GABA neurons. Inactivation of the BLA or intra-mPFC application of the AMPA/KA receptors antagonist, NBQX, attenuated both the conditioned LMA response to $\mathrm{COC}$ and the conditioned increase in $\mathrm{MPFC}$ GABA transmission indicating that BLA drive to the mPFC and the resulting activation of AMPA/KA receptors on GABA neurons mediates these effects. To our knowledge, the present study is the first to demonstrate a significant increase in mPFC GABA overflow in drug-free animals exposed to an environment previously associated with COC administration.

The mPFC contains intrinsic glutamatergic pyramidal neurons and GABA interneurons that receive glutamatergic afferents from the mediodorsal nucleus of the thalamus (Gabbott et al, 2005), the BLA (Bacon et al, 1996; McDonald, 1996; Gabbott et al, 2006) and hippocampus (Jay et al, 1992). In addition, GABAergic terminals arising from the ventral tegmental area (VTA) synapse on dendritic spines of both pyramidal output neurons and local interneurons (Carr and Sesack, 2000). Excitatory pyramidal neurons in turn innervate various sub-cortical structures including the VTA and NAc (Sesack and Pickel, 1992). Although cortical GABA interneurons are known to synapse on and modulate pyramidal neurons through local circuits, glutamatergic terminals also synapse on GABA neurons (Goldman-Rakic, 1999). These findings suggest the existence of reciprocal interactions between GLU and GABA neurons in the mPFC. Importantly, GABA interneurons exert powerful inhibitory control over the excitatory output of pyramidal neurons shaping the flow of information in the PFC (Constantinidis et al, 2002).

Recent studies have shown an association of mPFC GABA neurotransmission with the expression of COC-induced sensitization. Thus, repeated COC administration enhanced COC-induced mPFC GABA transmission in COC-sensitized rats during the first week of withdrawal (Jayaram and Steketee, 2005). The increase in mPFC GABA levels in response to a subsequent $\mathrm{COC}$ challenge was blocked by previous $\mathrm{MPFC}$ infusion of AMPA/KA antagonist DNQX, but not the NMDA antagonist CPP (Jayaram and Steketee, 2006). These data indicate that enhanced mPFC GABA transmission seen in COC-sensitized animals involves glutamatergic stimulation of AMPA receptors.

The present study shows a significant increase in $\mathrm{mPFC}$ GABA overflow in drug-free animals exposed to an environment previously associated with COC administration. No alteration in GABA overflow was observed in response to the SAL-associated environment or in pseudoconditioned control animals. These findings are important because they suggest that the increase in GABA transmission is selective and specifically reflects a conditioned response to COC-paired cues. To investigate whether the GABA increase is associated with activation of local GABA 
interneurons, we characterized cFos and $\mathrm{GAD}_{67}$ immunoreactivity in the mPFC following exposure to the COCassociated environmental cues. cFos-IR and the extent of cFos and $\mathrm{GAD}_{67}$ colocalization were significantly higher after exposure to the COC-paired environment than after exposure to the SAL-paired environment or in pseudoconditioned controls. These results indicate that presentation of COC-paired cues is associated with activation of GABA interneurons in the mPFC. In this regard, it is noteworthy that previous work has shown that in rats exhibiting COC-induced CPP, presentation of the COCpaired environment induced cFos activation in GABA, but not in pyramidal neurons, in the PrL area of the MPFC (Miller and Marshall, 2004). A subsequent study by the same authors (Miller and Marshall, 2005) revealed that exposure to COC-associated cues leads to greater activation of the efferents from the BLA to both the PrL cortex and NAc, whereas PrL output to the BLA and NAc is attenuated.

The above data suggests that enhanced mPFC GABA neurotransmission may be mediated by increased activity of afferents from the BLA. To test this hypothesis, we conducted microdialysis and immunohistochemical experiments in which the BLA was inactivated before presentation of the COC- or SAL-associated environments. The results of these experiments demonstrate that BLA inactivation prevents the increase in GABA overflow and $c$ Fos activation in $\mathrm{mPFC}$ GABA interneurons produced by exposure to the CAE. Evidence that BLA inactivation attenuates the conditioned LMA response to COC was also obtained. Together, these findings show the importance of BLA efferents for activation of mPFC GABA interneurons in the CAE.

GABA interneurons can be activated by both AMPA/KA and NMDA glutamatergic receptors (Rotaru et al, 2011). Microdialysis studies have shown that increases in $\mathrm{MPFC}$ GABA overflow induced by elevation of endogenous GLU levels are AMPA/KA, but not NMDA receptor mediated (Del and Mora, 1999). Moreover, COC-induced increases in mPFC GABA levels in animals exhibiting behavioral sensitization to COC is blocked by previous $\mathrm{MPFC}$ infusion of an AMPA/KA receptor antagonist, but not by a NMDA receptor antagonist (Jayaram and Steketee, 2006). Together, these data suggest that endogenous GLU acts preferentially through AMPA/KA receptors to increase GABAergic activity in the rat $\mathrm{mPFC}$. To assess the role of AMPA/KA receptors in mediating the conditioned increase in GABA overflow observed in the present study, NBQX was perfused into the mPFC via reverse dialysis and GABA overflow was quantified. NBQX treatment prevented the increase in GABA levels produced by exposure to the CAE demonstrating its dependence on AMPA/KA receptor activation. These data and the results of our inactivation studies indicate that exposure to COC-associated cues leads to an activation of glutamatergic efferents from the BLA to the mPFC, which in turn cause an activation of mPFC GABA neurons through an AMPA/KA receptor-dependent mechanism (Figure 7). Indeed, consistent with these findings, inactivation of the BLA or dorsal mPFC impairs contextual reinstatement of COC-seeking behavior (Fuchs et al, 2005).

Our microdialysis studies did not reveal an alteration in mPFC GLU overflow. Importantly, however, microdialysis may fail to sample synaptic pools of GLU, owing to rapid transporter-mediated clearance of this neurotransmitter, high levels of non-neuronal GLU in the extracellular space and variability of basal dialysate GLU levels (see Timmerman and Westerink, (1997) for review). Moreover, mPFC dialysate GLU concentrations reflect overflow not only from the BLA, but from other glutamatergic afferents including those projecting from the thalamus and hippocampus, as well as feedback collaterals from pyramidal neurons. Therefore, it is likely that increased GLU transmission resulting from activation of a specific afferent projection could be masked by opposing influences during in vivo microdialysis.

Recently, it was shown that re-exposure to heroinconditioned cues after cessation of heroin self-administration increases inhibitory GABAergic synaptic inputs onto mPFC pyramidal cells (Van den Oever et al, 2010). Thus, an increase in prefrontal GABA neurotransmission observed in this and the present study may be a common pathological process that underlies the development and or expression of conditioned drug/environment associations.

Using various neuroimaging approaches it has been shown that prefrontal cortex activity is reduced in opiate and psychostimulants addicts (Goldstein and Volkow, 2002; Goldstein et al, 2009a,b). However, exposure to cues previously associated with drug use, which provoke craving, induce marked PFC activation (Childress et al, 1988; Grant a Basal conditions.

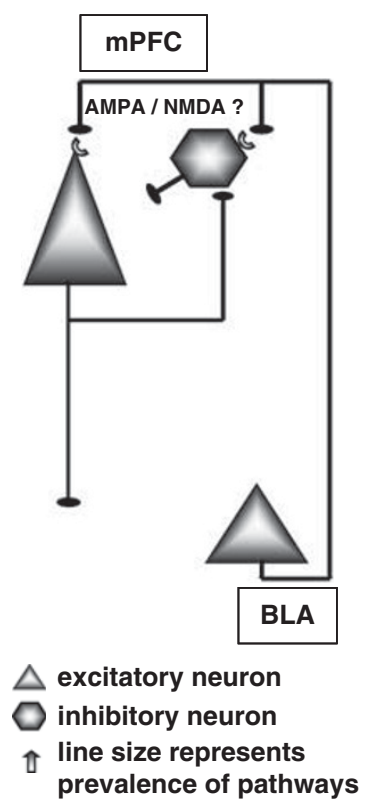

b Cocaine-associated environment.

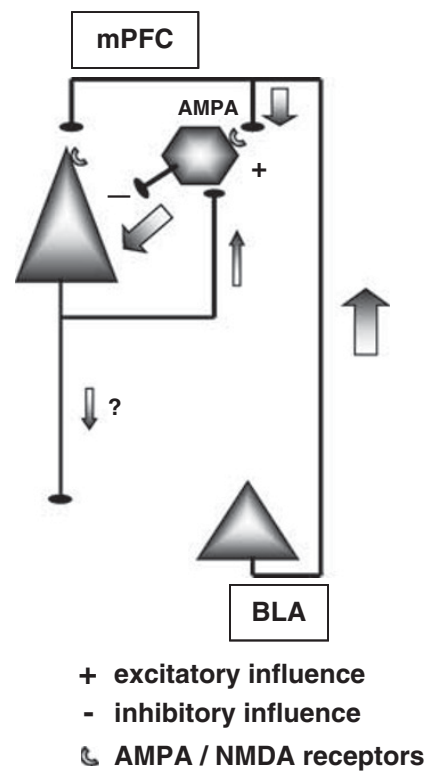

Figure 7 A simplified schematic illustration demonstrating some of the known functional connections between the BLA and PFC. Excitatory afferents from the BLA project to the apical dendrites of pyramidal neurons and to dendrites of fast-spiking GABA cells in the mPFC. These glutamatergic inputs are involved in transmitting salient associative information to target neurons within the PFC. For simplicity, we show only ascending PFC inputs from the BLA, however, PFC has functionally important ascending and descending projections from and to the NAc, VTA, locus coeruelus, raphe nuclei, and other neuromodulatory centers. (a) Baseline conditions. (b) When animals are introduced to environment previously associated with repeated cocaine administration, salient sensory information activates glutamatergic inputs from the BLA onto specific subpopulations GABAergic interneurons, which are sequentially excited through an AMPA/KA receptor-dependent mechanism. 
et al, 1996; Goldstein and Volkow, 2002). Yet, fundamental questions have remained as to how the intrinsic neurocircuitry of the corticolimbic system is altered. The present data demonstrating a significant induction of cFos immunoreactivity in GABA neurons and increased GABA overflow in the mPFC indicate that cue-evoked activation of intrinsic GABA neurons in the $\mathrm{mPFC}$ can occur after only limited drug/environmental cue exposure. Moreover, our studies suggest that increased GABAergic activity is due to BLA-driven activation of AMPA receptors located on intrinsic GABA neurons. The effects of long-term drug exposure are unknown and warrant future study. Overall, delineation of neurotransmitter interactions within the mPFC circuitry and how intrinsic (impulsivity traits) and extrinsic (eg, stress) factors affect the activity of this circuit may provide new insights as to the mechanisms by which stimuli associated with drug use drive behavior.

\section{ACKNOWLEDGEMENTS}

This work was supported by the US National Institutes of Health, the National Institute on Drug Abuse Intramural Research Program.

\section{DISCLOSURE}

The authors declare no conflict of interest.

\section{REFERENCES}

Bacon SJ, Headlam AJ, Gabbott PL, Smith AD (1996). Amygdala input to medial prefrontal cortex (mPFC) in the rat: a light and electron microscope study. Brain Res 720: 211-219.

Benes FM (2010). Amygdalocortical circuitry in schizophrenia: from circuits to molecules. Neuropsychopharmacology 35: 239-257.

Bonson KR, Grant SJ, Contoreggi CS, Links JM, Metcalfe J, Weyl HL et al (2002). Neural systems and cue-induced cocaine craving. Neuropsychopharmacology 26: 376-386.

Carr DB, Sesack SR (2000). GABA-containing neurons in the rat ventral tegmental area project to the prefrontal cortex. Synapse 38: 114-123.

Chefer VI, Czyzyk T, Bolan EA, Moron J, Pintar JE, Shippenberg TS (2005). Endogenous kappa-opioid receptor systems regulate mesoaccumbal dopamine dynamics and vulnerability to cocaine. J Neurosci 25: 5029-5037.

Chefer VI, Denoroy L, Zapata A, Shippenberg TS (2009). $\mathrm{Mu}$ opioid receptor modulation of somatodendritic dopamine overflow: GABAergic and glutamatergic mechanisms. Eur $J$ Neurosci 30: 272-278.

Childress AR, McLellan AT, Ehrman R, O'Brien CP (1988). Classically conditioned responses in opioid and cocaine dependence: a role in relapse? NIDA Res Monogr 84: 25-43.

Constantinidis C, Williams GV, Goldman-Rakic PS (2002). A role for inhibition in shaping the temporal flow of information in prefrontal cortex. Nat Neurosci 5: 175-180.

Crawford CA, McDougall SA, Bolanos CA, Hall S, Berger SP (1995). The effects of the kappa agonist U-50,488 on cocaine-induced conditioned and unconditioned behaviors and Fos immunoreactivity. Psychopharmacology (Berl) 120: 392-399.

Cunningham MG, Bhattacharyya S, Benes FM (2008). Increasing Interaction of amygdalar afferents with GABAergic interneurons between birth and adulthood. Cereb Cortex 18: 1529-1535.
Del AA, Mora F (1999). Effects of endogenous glutamate on extracellular concentrations of GABA, dopamine, and dopamine metabolites in the prefrontal cortex of the freely moving rat: involvement of NMDA and AMPA/KA receptors. Neurochem Res 24: 1027-1035.

Fuchs RA, Evans KA, Ledford CC, Parker MP, Case JM, Mehta RH et al (2005). The role of the dorsomedial prefrontal cortex, basolateral amygdala, and dorsal hippocampus in contextual reinstatement of cocaine seeking in rats. Neuropsychopharmacology 30: 296-309.

Gabbott PL, Warner TA, Busby SJ (2006). Amygdala input monosynaptically innervates parvalbumin immunoreactive local circuit neurons in rat medial prefrontal cortex. Neuroscience 139: 1039-1048.

Gabbott PL, Warner TA, Jays PR, Salway P, Busby SJ (2005). Prefrontal cortex in the rat: projections to subcortical autonomic, motor, and limbic centers. J Comp Neurol 492: 145-177.

Gibaldi M, Perier D (1975). The trapezoid rule. In: Gibaldi M, Perier D (eds). Pharmacokinetics. Marcel Dekker: New York, pp 293-296.

Goldman-Rakic PS (1999). The physiological approach: functional architecture of working memory and disordered cognition in schizophrenia. Biol Psychiatry 46: 650-661.

Goldstein RZ, Alia-Klein N, Tomasi D, Carrillo JH, Maloney T, Woicik PA et al (2009a). Anterior cingulate cortex hypoactivations to an emotionally salient task in cocaine addiction. Proc Natl Acad Sci USA 106: 9453-9458.

Goldstein RZ, Craig AD, Bechara A, Garavan H, Childress AR, Paulus MP et al (2009b). The neurocircuitry of impaired insight in drug addiction. Trends Cogn Sci 13: 372-380.

Goldstein RZ, Volkow ND (2002). Drug addiction and its underlying neurobiological basis: neuroimaging evidence for the involvement of the frontal cortex. Am J Psychiatry 159: $1642-1652$.

Grant S, London ED, Newlin DB, Villemagne VL, Liu X, Contoreggi C et al (1996). Activation of memory circuits during cue-elicited cocaine craving. Proc Natl Acad Sci USA 93: 12040-12045.

Holland PC, Bouton ME (1999). Hippocampus and context in classical conditioning. Curr Opin Neurobiol 9: 195-202.

Jay TM, Thierry AM, Wiklund L, Glowinski J (1992). Excitatory amino acid pathway from the hippocampus to the prefrontal cortex. Contribution of AMPA receptors in hippocampoprefrontal cortex transmission. Eur J Neurosci 4: 1285-1295.

Jayaram P, Steketee JD (2005). Effects of cocaine-induced behavioural sensitization on GABA transmission within rat medial prefrontal cortex. Eur J Neurosci 21: 2035-2039.

Jayaram P, Steketee JD (2006). Cocaine-induced increases in medial prefrontal cortical GABA transmission involves glutamatergic receptors. Eur J Pharmacol 531: 74-79.

Kalivas PW, McFarland K (2003). Brain circuitry and the reinstatement of cocaine-seeking behavior. Psychopharmacology (Berl) 168: 44-56.

Kalivas PW, Peters J, Knackstedt L (2006). Animal models and brain circuits in drug addiction. Mol Interv 6: 339-344.

Maas LC, Lukas SE, Kaufman MJ, Weiss RD, Daniels SL, Rogers VW et al (1998). Functional magnetic resonance imaging of human brain activation during cue-induced cocaine craving. Am J Psychiatry 155: 124-126.

McDonald AJ (1996). Glutamate and aspartate immunoreactive neurons of the rat basolateral amygdala: colocalization of excitatory amino acids and projections to the limbic circuit. J Comp Neurol 365: 367-379.

Miller CA, Marshall JF (2004). Altered prelimbic cortex output during cue-elicited drug seeking. J Neurosci 24: 6889-6897.

Miller CA, Marshall JF (2005). Altered Fos expression in neural pathways underlying cue-elicited drug seeking in the rat. Eur $J$ Neurosci 21: 1385-1393. 
O’Brien CP, Childress AR, McLellan AT (1991). Conditioning factors may help to understand and prevent relapse in patients who are recovering from drug dependence. NIDA Res Monogr 106: 293-312.

Paxinos G, Watson C (1998). The Rat Brain in Stereotaxic Coordinates. Academic Press: San Diego.

Peters J, Vallone J, Laurendi K, Kalivas PW (2008). Opposing roles for the ventral prefrontal cortex and the basolateral amygdala on the spontaneous recovery of cocaine-seeking in rats. Psychopharmacology (Berl) 197: 319-326.

Petrovich GD, Gallagher M (2003). Amygdala subsystems and control of feeding behavior by learned cues. Ann N Y Acad Sci 985: 251-262.

Rotaru DC, Yoshino H, Lewis DA, Ermentrout GB, GonzalezBurgos G (2011). Glutamate receptor subtypes mediating synaptic activation of prefrontal cortex neurons: relevance for schizophrenia. J Neurosci 31: 142-156.

Sesack SR, Pickel VM (1992). Prefrontal cortical efferents in the rat synapse on unlabeled neuronal targets of catecholamine terminals in the nucleus accumbens septi and on dopamine neurons in the ventral tegmental area. J Comp Neurol 320: $145-160$.
Timmerman W, Westerink BH (1997). Brain microdialysis of GABA and glutamate: what does it signify? Synapse 27: 242-261.

Tzschentke TM, Schmidt WJ (1999). Functional heterogeneity of the rat medial prefrontal cortex: effects of discrete subarea-specific lesions on drug-induced conditioned place preference and behavioural sensitization. Eur J Neurosci 11: 4099-4109.

Van den Oever MC, Lubbers BR, Goriounova NA, Li KW, Van der Schors RC, Loos M et al (2010). Extracellular matrix plasticity and GABAergic inhibition of prefrontal cortex pyramidal cells facilitates relapse to heroin seeking. Neuropsychopharmacology 35: $2120-2133$.

Weissenborn R, Robbins TW, Everitt BJ (1997). Effects of medial prefrontal or anterior cingulate cortex lesions on responding for cocaine under fixed-ratio and second-order schedules of reinforcement in rats. Psychopharmacology (Berl) 134: 242-257.

Wikler A (1973). Dynamics of drug dependence. Implications of a conditioning theory for research and treatment. Arch Gen Psychiatry 28: 611-616.

Zombeck JA, Chen GT, Johnson ZV, Rosenberg DM, Craig AB, Rhodes JS (2008). Neuroanatomical specificity of conditioned responses to cocaine $v s$ food in mice. Physiol Behav 93: 637-650.

Supplementary Information accompanies the paper on the Neuropsychopharmacology website (http://www.nature.com/npp) 